\title{
COMPOSITION OF A CLEAN AND SULPHUR COVERED CuNi(100) SINGLE CRYSTAL SURFACE
}

\author{
P.J. GodowsKi" and P. Marcus
}

Laboratoire de Physico-Chimie des Surfaces, CNRS (URA 425), Université Paris VI ENSCP, 11, Rue Pierre et Marie Curie, 75231 Paris Cedex 05, France

\author{
(Received July 5, 1994; revised version September 13, 1994; \\ in final form December 28, 1994)
}

\begin{abstract}
Surface composition of the $\mathrm{CuNi}(100)$ single crystal in the temperature range of $893 \div 1073 \mathrm{~K}\left(620 \div 800^{\circ} \mathrm{C}\right)$ has been investigated using low energy electron diffraction and Auger electron spectroscopy methods. A clean sample surface at moderate temperatures reveals small surface copper enrichment, with respect to the bulk Cu-rich composition. For example, at $1006 \mathrm{~K}$ $\left(733^{\circ} \mathrm{C}\right)$ the copper surface concentration $C_{\mathrm{Cu}}^{\mathrm{s}}$, was determined from the quantitative Auger electron spectroscopy analysis as 0.91 . After prolonged heating at higher temperatures, the copper surface concentration converges to the bulk value, i.e. at $1073 \mathrm{~K}\left(800^{\circ} \mathrm{C}\right), C_{\mathrm{Cu}}^{\mathrm{s}}=C_{\mathrm{Cu}}^{\mathrm{b}}=0.87$. Surface segregation of sulphur proceeds from $(1 \times 1)$ through $p(2 \times 2) \mathrm{S} / \mathrm{CuNi}(100)$ to $c(2 \times 2) \mathrm{S} / \mathrm{CuNi}(100)$ structures of low energy electron diffraction. In the presence of segregated sulphur the surface concentration of copper is lower.
\end{abstract}

PACS numbers: 68.35.Dv, 82.80.Pv, 61.14.Hg

\section{Introduction}

A $\mathrm{Cu}_{x} \mathrm{Ni}_{1-x}$ alloy has been extensively studied because of its application in catalysis (the range of $0 \div 10$ at.\% of $\mathrm{Cu}$, i.e. modified of $\mathrm{Ni}$ catalyst by small amount of $\mathrm{Cu}$ ) and metallurgy (the other extreme range $0 \div 10$ at.\% of $\mathrm{Ni}$ ) [1, 2]. It has a simple phase diagram, i.e. it forms a solid solution over the whole range of composition and is stable up to high temperatures. Relative differences of atomic density, atomic mass, cohesive energy and electronegativity of each element are within $1 \%$, therefore the alloy can be thought as a model system. It has been

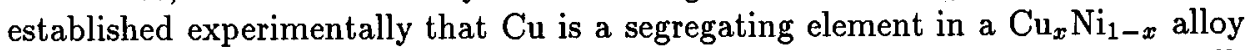
for polycrystalline and low index single crystal planes over a wide range of bulk alloy compositions $[3,4]$. Together with experimental data, a number of theoretical papers have been reported which confirm $\mathrm{Cu}$ segregation behavior but differ in

* Guest scientist from W. Trzebiatowski Institute of Low Temperature and Structure Research, Polish Academy of Sciences, P.O. Box 937, 50-950 Wrocław, Poland. 
the levels of the segregants on the surface. A very sophisticated microscopic model presented by Cheng [5] predicts the so-called crossover phenomenon in the surface segregation of $\mathrm{Cu}_{x} \mathrm{Ni}_{1-x}$ alloy. In this approximation, $\mathrm{Cu}$ atoms segregate to the surface of $\mathrm{Cu}_{x} \mathrm{Ni}_{1-x}$ in the composition range of $0 \leq x \leq 0.75$. In the Cu-rich alloy of $0.75<x \leq 1$ range, segregation of $N_{1}$ aloms to the surface is obtained. The model explains the experimental results of Sakurai et al. [6], who reported a crossover at $x=0.84$.

Due to different sputtering yields, $\mathrm{Ar}^{+}$bombardment of alloy surfaces alters the composition of the near surface region. For the $\mathrm{Cu}_{x} \mathrm{Ni}_{1-x}$ alloy controversial results have been published, ion bombardment leading to enrichment of nickel (e.g. [7]) or copper (e.g. [4]).

In this paper an investigation of surface segregation of a clean and sulphur contaminated surface of $\mathrm{Cu}$-rich $\mathrm{Cu}_{x} \mathrm{Ni}_{1-x}$ alloy is presented. The aim of this work was to clear up the controversy existing in the literature, especially to test the crossover phenomenon.

\section{Experimental}

The ultrahigh vacuum (UHV) system consisted of a Varian chamber pumped by the $200 \mathrm{l} \mathrm{sec}^{-1}$ Riber ion pump and the assembly of gases dosing $\left(\mathrm{Ar}_{2}\right.$ and $\left.\mathrm{O}_{2}\right)$. The chamber was equipped with a cylindrical mirror analyzer (CMA) with an integrated electron gun (Riber, model OPC 105), a four-grid low energy electron diffraction (LEED)/Auger electron spectroscopy (AES) optics (Riber, model OPD 304), a manipulator of high precision (Riber, model TUM-3) and an ion bombardment gun (Varian, model 981). The base pressure in the system after backing out at $400 \mathrm{~K}\left(130^{\circ} \mathrm{C}\right)$ for 10 hours did not exceed $5 \times 10^{-7} \mathrm{~Pa}$. Auger spectra were recorded in the differential mode, $\mathrm{d} N(E) / \mathrm{d} E$, with the electron incident beam of $2.5 \mathrm{keV}$ energy and $10 \mu \mathrm{A}$ current using $3 V_{\mathrm{pp}}$ modulation voltage to the CMA. The emission current of the LEED gun, working at $30 \div 200 \mathrm{eV}$ range, was about $15 \mu \mathrm{A}$.

The $\mathrm{Cu}_{x} \mathrm{Ni}_{1-x}$ single crystal sample, with a composition close to $x=0.90$, was oriented along the desired (100) crystallographic direction within $\pm 1^{\circ}$ using $\mathrm{X}$-ray diffraction. It had the shape of a disc about $10 \mathrm{~mm}$ diameter and $3 \mathrm{~mm}$ thick. After cutting by a spark-erosion machine and checking the orientation, the specimen was mechanically polished with diamond abrasives to get a good quality surface with mirror finish. To avoid creation of etch pits on the surface, the sample was not electrolytically polished, but before mounting to the holder it was washed in acetone in an ultrasonic bath for approximately $10 \mathrm{~min}$. A loop of tungsten wire (of $\varnothing 0.5 \mathrm{~mm}$ ) was inserted through holes drilled in the specimen and the loop was fixed to the molybdenum rods on the manipulator. The Pt-PtRh10\% thermocouple was mechanically fixed in a hole made in the upper part of the sample. A sketch of a heating device is shown in Fig. 1. By passing a.c. current through the device, the specimen could be heated by thermal conduction from a heating tungsten loop. This stage allowed Auger intensity measurements at temperature with negligible peak attenuation from the residual magnetic field. Some investigators shut the heating current off during the Auger measurements, but this was shown to produce a significant error due to the segregation during cooling the specimen [8]. 


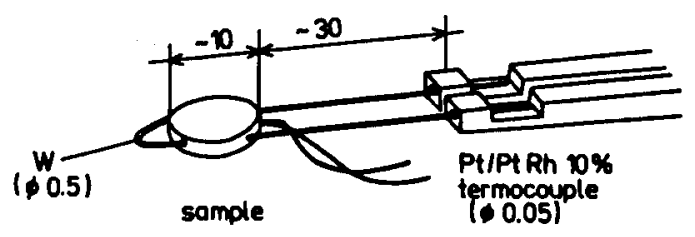

Fig. 1. Heating stage used in the experiment.

Iligh purity (99.999\%) copper and nickel foils, $0.125 \mathrm{~mm}$ thick, were used for measuring the reference spectra in separate experiments. Two pieces of each foil, with dimensions of approximately $3 \times 15 \mathrm{~mm}^{2}$, were mounted to the two heating tungsten wires $(\varnothing 0.5 \mathrm{~mm}$ ) and the assembly was attached to the molybdenum rods on the manipulator. In this case, the thermocouple was not fixed to the reference samples and the temperature of the foils was controlled with an optical pyrometer.

\section{Data analysis - quantitative AES}

The copper-nickel alloy is a good system for quantification in AES, because the so-called matrix effects are negligible. Thus, the equations do not require the corrections for back scattered electrons, atomic density and electron escape depth. The surface composition can be assessed directly by the Auger signal intensities from the alloy and two standards. For a homogeneous $\mathrm{Cu}_{x} \mathrm{Ni}_{1-x}$ alloy, the Auger signals, $I$, corresponding to the constituents are as follows:

$$
\begin{aligned}
& I_{\mathrm{Cu}}\left(C_{\mathrm{Cu}}^{\mathrm{b}}\right)=I_{\mathrm{Cu}}^{0} C_{\mathrm{Cu}}^{\mathrm{b}}, \\
& I_{\mathrm{Ni}}\left(C_{\mathrm{Ni}}^{\mathrm{b}}\right)=I_{\mathrm{Ni}}^{0} C_{\mathrm{Ni}}^{\mathrm{b}},
\end{aligned}
$$

where $C_{\mathrm{Cu}}^{\mathrm{b}}$ and $C_{\mathrm{Ni}}^{\mathrm{b}}$ denote the bulk concentrations (in at.\%) of copper and nickel, respectively. $I^{0}$ denotes the Auger intensity of the pure element. Using the ratio of signals, $i=I_{\mathrm{Ni}} / I_{\mathrm{Cu}}, i_{0}=I_{\mathrm{Ni}}^{0} / I_{\mathrm{Cu}}^{0}$, and remembering that $C_{\mathrm{Cu}}^{\mathrm{b}}+C_{\mathrm{Ni}}^{\mathrm{b}}=1$ for the substitutional solid solution we have

$$
C_{\mathrm{Cu}}^{\mathrm{b}}=\frac{i_{0}}{i_{0}+i}
$$

When the concentration of the first layer differs from that of the other layers having an average bulk composition, the formula must be divided into two terms and in the case of a discrete model (i.e. a sum of contribution from each layer) [9] we have

$$
\begin{aligned}
& I_{\mathrm{Cu}}=I_{\mathrm{Cu}}^{0}\left\{\left[1-\exp \left(-d / \Lambda_{\mathrm{Cu}}\right)\right] C_{\mathrm{Cu}}^{\mathrm{s}}+C_{\mathrm{Cu}}^{\mathrm{b}} \exp \left(-d / \Lambda_{\mathrm{Cu}}\right)\right\}, \\
& I_{\mathrm{Ni}}=I_{\mathrm{Ni}}^{0}\left\{\left[1-\exp \left(-d / \Lambda_{\mathrm{Ni}}\right)\right] C_{\mathrm{Ni}}^{\mathrm{s}}+C_{\mathrm{Ni}}^{\mathrm{b}} \exp \left(-d / \Lambda_{\mathrm{Ni}}\right)\right\},
\end{aligned}
$$

where the average monolayer thickness $d$, in $\mathrm{nm}$, is calculated from $d=C_{\mathrm{Cu}}^{\mathrm{bu}} d_{\mathrm{Cu}}+$ $C_{\mathrm{Ni}}^{\mathrm{b}} d_{\mathrm{Ni}}, \Lambda$ is the electron escape depth, expressed in $\mathrm{nm}$, for CMA $\Lambda=0.74 \lambda$, where $\lambda$ is the attenuation length. Using the ratio of signals and rearranging the equations we obtain 


$$
C_{\mathrm{Cu}}^{\mathrm{s}}=\frac{1-C_{\mathrm{Cu}}^{\mathrm{b}}\left[\exp \left(-d / \Lambda_{\mathrm{Ni}}\right)+\frac{i}{i_{0}} \exp \left(-d / \Lambda_{\mathrm{Cu}}\right)\right]}{1-\exp \left(-d / \Lambda_{\mathrm{Ni}}\right)+\frac{i}{i_{0}}\left[1-\exp \left(-d / \Lambda_{\mathrm{Cu}}\right)\right]} .
$$

The above formulas (3) and (6) were used for the investigated $\mathrm{Cu}_{x} \mathrm{Ni}_{1-x}(100)$ alloy surface depending on the model employed. As the source of the attenuation length, the compilation of experimental data of [10] was chosen. Although more recent theoretical evaluation of the parameters describing the electron transport in the solid appeared in the literature (e.g. [11]), we decided to perform our analysis on the basis of experimental data only.

The reference samples used in the study have different structures from the studied alloy and the significance of the crystalline order of the sample on the observed Auger peak intensities should be discussed. Crystalline effects, although natural in their origin - diffraction of the ingoing primary electron beam or/and outgoing Auger electrons - could not be easily taken into account as an analog equation or simply as a factor in the formulas $[12,13]$. Segregation experiments are usually connected with the Auger measurements at temperatures as high as $0.8 T_{\mathrm{M}}$, where $T_{\mathrm{M}}$ denotes melting points of the sample. Diffraction of the involved electrons at the temperatures used here, i.e. in the range of $893 \div 1073 \mathrm{~K}$, simply disappears. For this reason, the polycrystalline standards fully accomplish the requirements of correct experimental conditions for the use of the above equations.

\section{Results and discussion}

\subsection{Preparation and characterization}

After mounting the $\mathrm{CuNi}(100)$ sample in the UHV chamber and heating for $20 \mathrm{~min}$. at $933 \mathrm{~K}\left(660^{\circ} \mathrm{C}\right)$, the following contaminants were detected: sulphur, carbon and a small quantity of oxygen. Prolonged ( 5 hours) heating at moderate temperatures, e.g. at $853 \mathrm{~K}\left(580^{\circ} \mathrm{C}\right)$, produced oxygen desorption and an increase in surface carbon content due to the out-diffusion of carbon. During heating the sample at higher temperatures, e.g. at $973 \mathrm{~K}\left(700^{\circ} \mathrm{C}\right)$ for 1 hour, the surface concentration of carbon decreased, but sulphur appeared on the surface (Fig. 2). The sample surface with segregated contaminants was treated in oxygen with exposures of the order of $10^{4}$ Langmuirs $\left(1 \mathrm{~L}=10^{-6}\right.$ torr s) at $973 \mathrm{~K}\left(700^{\circ} \mathrm{C}\right)$, heated at $1023 \mathrm{~K}\left(750^{\circ} \mathrm{C}\right)$ for approximately $30 \mathrm{~min}$. to remove any excess of oxygen and finally bombarded by argon ions $\left(p_{\mathrm{Ar}}=2 \times 10^{-5}\right.$ torr, $V_{\mathrm{Ar}}=1 \mathrm{keV}$, $i_{\mathrm{Ar}}=10 \mu \mathrm{A} \mathrm{cm}{ }^{-2}$ ) for 20-30 min. Such a procedure of combined chemical cleaning of metal surfaces in UHV and ion bombardment remove contaminants very effectively $[14,15]$. The surface region after this procedure could be depleted not only of contaminants but also of the most volatile alloy component as well, i.e. copper. Then, the alloy was homogenized in UHV by heating at $973 \mathrm{~K}\left(700^{\circ} \mathrm{C}\right)$ for 60 hours. Depending on the extent of the previous oxygen treatment, heating conditions activated (or not) the segregation of sulphur to the surface in the sample. Reproducibility of results was checked by taking several sets of measurements. For some experiments the sample was prepared once again, i.e. it was taken out of the UHV chamber and mechanically abraded to create a "new" surface. 

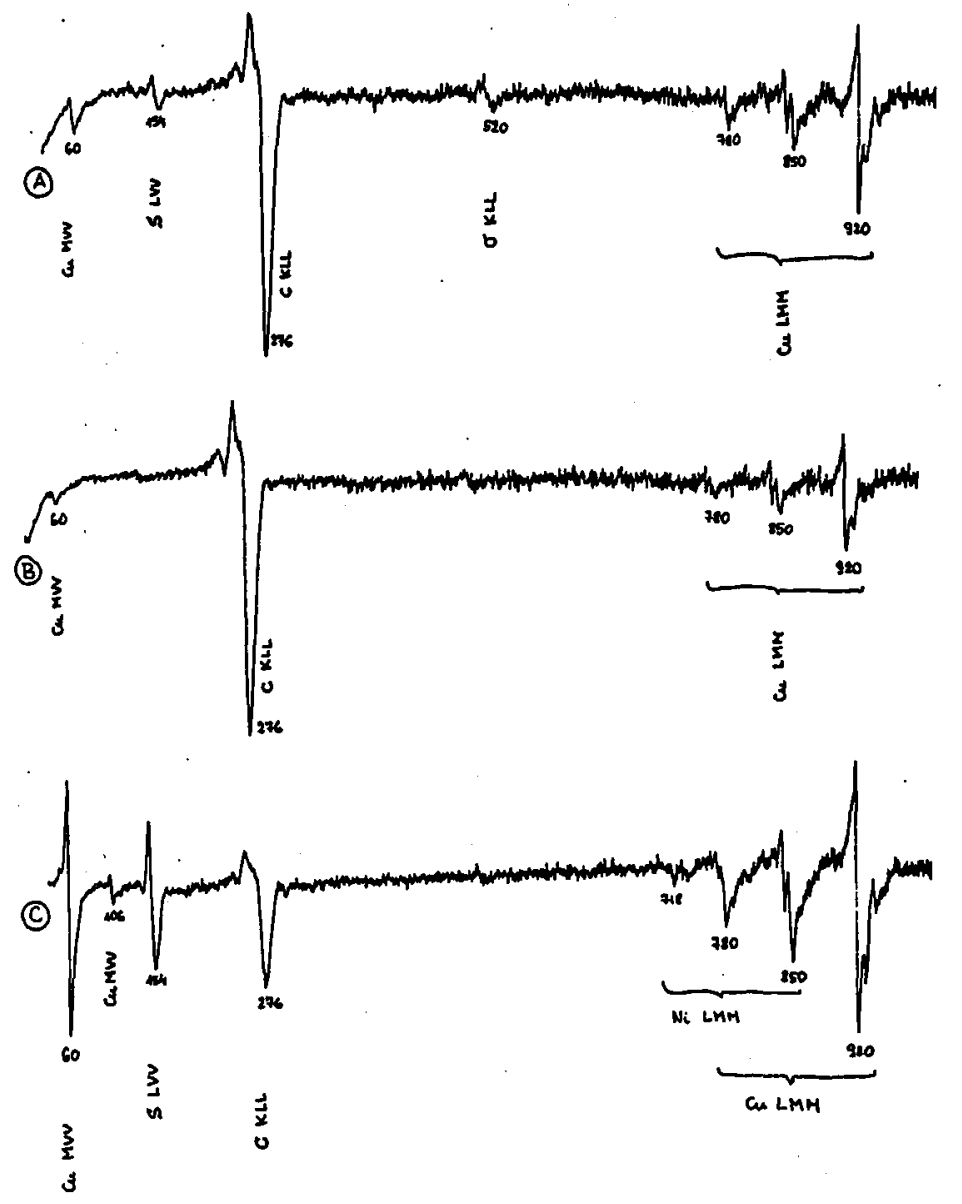

Fig. 2. Auger spectrum from a $\mathrm{Cu}_{x} \mathrm{Ni}_{1-x}(100)$ sample, (a) after $20 \mathrm{~min}$. heating at $933 \mathrm{~K},(\mathrm{~b})$ after 5 hours heating at $853 \mathrm{~K}$, (c) after 1 hour heating at $973 \mathrm{~K}$.

The copper and nickel reference spectra from polycrystalline foils of high purity were obtained using the CMA working at the same excitation and detection conditions for all the experiments. The foils were cleaned by a combination of oxygen exposure at $973 \mathrm{~K}\left(700^{\circ} \mathrm{C}\right)$, heating at $1073 \mathrm{~K}\left(800^{\circ} \mathrm{C}\right)$ and argon ion bombardment ( $p_{\mathrm{Ar}}=2 \times 10^{-5}$ torr, $V_{\mathrm{Ar}}=1 \mathrm{keV}, i_{\mathrm{Ar}}=10 \mu \mathrm{A} \mathrm{cm}{ }^{-2}$ ) for similar time periods as in the case of the alloy.

Differential AES spectra of $\mathrm{Cu}$ and Ni consist of two major groups of peaks, low energy ones corresponding to a MVV-type transition and high energy to a LVV group of transition (Table I). To avoid a number of fine splittings, especially in the high energy LVV (i.e. in three groups: $L_{3} M_{23} M_{23}, L_{3} M_{23} M_{45}$ and $\mathrm{L}_{3} \mathrm{M}_{45} \mathrm{M}_{45}$ ) [16], the spectra were taken in the conditions of moderate resolution as usual for quantification. In the alloy, the low energy MVV peaks of $\mathrm{Ni}$ and $\mathrm{Cu}$ strongly overlap and are unresolved. consequently the LVV peaks were chosen for 
TABLE I

Characteristic values of nickel and copper reference Auger spectra in the $\mathrm{d} N(E) / \mathrm{d} E$ mode. Relative intensities were derived experimentally on the basis of the handbook of Auger electron spectroscopy [17], using the peak-to-peak heights in the derivative spectra for $3 \mathrm{keV}$ electrons at normal incidence. Attenuation lengths, $\lambda$, were determined from Seah and Dench formula [10], $\lambda=\left[538 / E^{2}+0.42(a E)^{1 / 2}\right] a$, where the monolayer (ML) thickness of nickel and copper were $a_{\mathrm{Ni}}=0.222 \mathrm{~nm}$ and $a_{\mathrm{Cu}}=0.228 \mathrm{~nm}$.

\begin{tabular}{|c|c|c|c|c|}
\hline Auger transition & $\begin{array}{c}\text { Relative } \\
\text { intensity } \\
I_{i} / I_{\mathrm{Ag}}\end{array}$ & $\begin{array}{c}\text { Kinetic } \\
\text { energy } \\
{[\mathrm{eV}]}\end{array}$ & \multicolumn{2}{|c|}{$\begin{array}{l}\text { Electron escape depth } \\
\text { (CMA), } \Lambda=0.74 \lambda\end{array}$} \\
\hline $\mathrm{Ni} \mathrm{M}_{23} \mathrm{M}_{45} \mathrm{M}_{45}$ & 0.263 & 62 & 0.273 & 1.23 \\
\hline $\mathrm{Ni} \mathrm{M}_{1} \mathrm{M}_{45} \mathrm{M}_{45}$ & 0.026 & 103 & 0.330 & 1.49 \\
\hline $\mathrm{Ni} \mathrm{L} \mathrm{L}_{23} \mathrm{M}_{23}$ & 0.062 & 718 & 0.851 & 3.83 \\
\hline $\mathrm{Ni} \mathrm{L}_{3} \mathrm{M}_{23} \mathrm{M}_{45}$ & 0.100 & 782 & 0.888 & 4.00 \\
\hline $\mathrm{Ni} \mathrm{L}_{3} \mathrm{M}_{45} \mathrm{M}_{45}$ & 0.255 & 850 & 0.925 & 4.17 \\
\hline $\mathrm{Cu} \mathrm{M}_{23} \mathrm{M}_{45} \mathrm{M}_{45}$ & 0.298 & 60 & 0.281 & 1.23 \\
\hline $\mathrm{Cu} \mathrm{M}_{1} \mathrm{M}_{45} \mathrm{M}_{45}$ & 0.039 & 106 & 0.348 & 1.53 \\
\hline $\mathrm{Cu} \mathrm{L}{ }_{3} \mathbf{M}_{23} \mathbf{M}_{23}$ & 0.042 & 780 & 0.923 & 4.05 \\
\hline $\mathrm{Cu} \mathrm{L} \mathrm{L}_{3} \mathrm{M}_{23} \mathrm{M}_{45}$ & 0.070 & 850 & 0.963 & 4.22 \\
\hline $\mathrm{Cu} \mathrm{L} \mathrm{L}_{3} \mathrm{M}_{45} \mathrm{M}_{45}$ & 0.238 & 920 & 1.000 & 4.39 \\
\hline
\end{tabular}

a quantitative analysis. Between the nickel $\mathrm{L}_{3} \mathrm{M}_{23} \mathrm{M}_{45}$ transition and the copper $\mathrm{L}_{3} \mathrm{M}_{23} \mathrm{M}_{23}$ and the nickel $\mathrm{L}_{3} \mathrm{M}_{45} \mathrm{M}_{45}$ and the copper $\mathrm{L}_{3} \mathrm{M}_{23} \mathrm{M}_{45}$ there exists overlaps as well. Thus, the $\mathrm{L}_{3} \mathrm{M}_{23} \mathrm{M}_{23}$ peak of nickel at $718 \mathrm{eV}$ and the $\mathrm{L}_{3} \mathrm{M}_{45} \mathrm{M}_{45}$ peak of copper at $920 \mathrm{eV}$ were taken for quantification in the $\mathrm{CuNi}(100)$ sample. Two types of the signal for.Auger electron current in $\mathrm{d} N(E) / \mathrm{d} E$ spectra are in the current use, the peak-to-peak $(p / p)$ height and the background-to-peak $(b / p)$ depth. The ratio of intensities from reference spectra, $i_{0}=I_{\mathrm{Ni}}^{0} / I_{\mathrm{Cu}}^{0}$, was determined as $0.52 \pm 0.02$ for $b / p$ depths and $0.42 \pm 0.02$ for $p / p$ heights. The values represent the average of around twenty analyses performed on different places of the same reference specimen. For comparison, the $\mathrm{Ni} / \mathrm{Cu}$ ratios of the handbook of elemental spectra [17] are 0.31 and 0.26 , for $b / p$ depths and $p / p$ heights, respectively.

Investigations of the equilibrium surface composition require the lengthy process of ion bombardment and heating under ultra-high vacuum conditions. These treatments can change the contents of constituents in the subsurface region and this may result in no true equilibrium surface being obtained. Argon ion bombardment itself alters the surface composition away from the ideal case mainly due to difference of sputtering yield of each component. The concentration of the element with the lower sputtering yield increases in surface layers and after some time of sputtering it reaches a stationary value. It was shown [18] that the 
equilibrium surface content of the $\mathrm{Cu}_{58} \mathrm{Ni}_{42}$ alloy, was obtained after $10 \mathrm{~min}$. of $500 \mathrm{eV} \mathrm{Ar}{ }^{+}$bombardment with the current density of $15 \mu \mathrm{A} \mathrm{cm}^{-2}$. For an $\mathrm{AB}$ alloy, the stationary value of the surface concentration can be evaluated using the simple formula $[18,19]$

$$
C_{\mathrm{A}}^{\mathrm{s}}(\text { equilibrium })=\left[\left(S_{\mathrm{B}} / S_{\mathrm{A}}\right) C_{\mathrm{A}}^{\mathrm{b}}\right] /\left[1-C_{\mathrm{A}}^{\mathrm{b}}+\left(S_{\mathrm{B}} / S_{\mathrm{A}}\right) C_{\mathrm{A}}^{\mathrm{b}}\right],
$$

where $C_{\mathrm{A}}^{\mathrm{s}}$ and $C_{\mathrm{A}}^{\mathrm{b}}$ are the surface and the bulk concentrations, respectively, expressed in atomic per cent and $S_{\mathrm{A}}$ and $S_{\mathrm{B}}$ denote the sputtering yields in atom ion ${ }^{-1}$, for the $\mathrm{A}$ and $\mathrm{B}$ components of the binary alloy. The sputtering yield was found to be in a simple relation with the inverse heat of sublimation of the element, so the bond energies between atoms resist the ejection mechanism. Several experimental values of sputtering yields for nickel and copper have been presented [18-22] and the sputtering yield ratio, $S_{\mathrm{Cu}} / S_{\mathrm{Ni}}$, of $1.7 \pm 0.2$ for $0.5 \div 2.0 \mathrm{keV}$ $\mathrm{Ar}^{+}$ions is the most frequently used value [22]. Introducing the above sputtering yield ratios into Eq. (7), the equilibrium surface concentration of the elements of the alloy were evaluated. Starting from the surface composition equal to the bulk value of the $\mathrm{Cu}_{x} \mathrm{Ni}_{1-x}(100), x=0.90$ alloy, after $\mathrm{Ar}^{+}$bombardment used in this work, the nickel surface concentration of $C_{\mathrm{Ni}}^{\mathrm{s}}=0.16$ could be expected. This evaluation shows that a sputtering effect during cleaning the sample surface disturbs its content in a non-negligible manner.

The second phenomenon which affects the surface composition and leads to an irreversible loss of one alloy component is surface evaporation of segregant. In agreement with mass balance, to obtain an excess segregant coverage on the surface, several layers of bulk must be depleted. The depleted near surface region can be restored to equilibrium by annealing the sample for a very long time. In the $\mathrm{Cu}_{x} \mathrm{Ni}_{1-x}$ alloy, copper evaporates preferentially due to the higher $\mathrm{Cu}$ vapor pressure than $\mathrm{Ni}$ at the same temperature (e.g. at $1090 \mathrm{~K}, p_{\mathrm{Ni}}=1 \times 10^{-10}$ torr and at $1060 \mathrm{~K}, p_{\mathrm{Cu}}=1 \times 10^{-7}$ torr [23]). It was reported [24] that above $1080 \mathrm{~K}$ $\left(807^{\circ} \mathrm{C}\right)$ evaporation of copper in $\mathrm{Cu}_{5} \mathrm{Ni}_{95}(100)$ is not negligible. Evaporation of sulphur can be expected at slightly higher temperatures, e.g. sulphur evaporate at around $1130 \mathrm{~K}\left(857^{\circ} \mathrm{C}\right)$ from the surface of the $\mathrm{Co}_{50} \mathrm{Ni}_{50}$ alloy [25]. For these reasons, in the first approximation, the limiting temperature of $1080 \mathrm{~K}\left(807^{\circ} \mathrm{C}\right)$ was chosen for the present investigation.

\subsection{Surface composition of the $C u_{x} N i_{1-x}(100)$ alloy}

After cleaning and homogenization of the sample, which gave a clear $(1 \times 1)$ LEED pattern, the high energy Auger peaks as functions of sample temperature were monitored. The experiment was performed in an increasing temperature mode. The sample was heated at a given temperature for a sufficiently long time and then, the temperature was increased in some interval. Auger spectra were registered without switching off the heating current and each measurement point consisted of the high energy region of the $\mathrm{d} N(E) / \mathrm{d} E$ monitored several times. The sample was heated in the following conditions: 24 hours at $917 \pm 20 \mathrm{~K}\left(644 \pm 20^{\circ} \mathrm{C}\right)$, 12 hours at $1006 \pm 10 \mathrm{~K}\left(733 \pm 10^{\circ} \mathrm{C}\right), 7$ hours at $1030 \pm 10 \mathrm{~K}\left(757 \pm 10^{\circ} \mathrm{C}\right)$ and 1.5 hour at $1073 \pm 10 \mathrm{~K}\left(800 \pm 10^{\circ} \mathrm{C}\right)$. At each temperature, the little changes in Auger intensities with time of heating (segregation kinetics) were observed. On the basis 


\section{TABLE II}

The Auger b/p depths ratio of $\mathrm{Ni}(718 \mathrm{eV}, \mathrm{LVV})$ to $\mathrm{Cu}(920 \mathrm{eV}$, LVV) for the $\mathrm{Cu}_{x} \mathrm{Ni}_{1-x}(100)$ alloy after heating at the indicated temperatures. The surface concentrations, $C_{\mathrm{Cu}}^{\mathrm{av}}$ and $C_{\mathrm{Cu}}^{\mathrm{s}}$ were determined using Eqs. (3) and (8), respectively.

\begin{tabular}{l|c|c|c|c}
\hline \hline Temperature $[\mathrm{K}]$ & 917 & 1006 & 1030 & 1073 \\
\hline$I_{\mathrm{Ni}}(718) / I_{\mathrm{Cu}}(920)$ & 0.072 & 0.072 & 0.073 & 0.078 \\
$C_{\mathrm{Cu}}^{\mathrm{av}}$ & 0.88 & 0.88 & 0.88 & 0.87 \\
$C_{\mathrm{Cu}}^{\mathrm{s}}$ & 0.91 & 0.91 & 0.90 & 0.87
\end{tabular}

TABLE III

The physical parameters used in AES quantification.

\begin{tabular}{l|c|c|c}
\hline \hline & ${ }^{28} \mathrm{Ni}$ & ${ }^{29} \mathrm{Cu}$ & $\begin{array}{c}\mathrm{Cu}_{90} \mathrm{Ni}_{10} \\
\text { (average) }\end{array}$ \\
\hline $\begin{array}{l}\text { Density [g/ml] } \\
\text { Atomic weight }\end{array}$ & $\begin{array}{c}8.9 \\
\text { Monolayer thickness, }\end{array}$ & 8.96 & \\
$\begin{array}{l}d \text { [nm] } \\
\text { Kinetic energy of }\end{array}$ & 0.222 & 0.228 & 0.227 \\
Auger transition & 718 & 920 & \\
Electron escape & & & \\
depth [nm] & 0.851 & 1.00 & \\
exp(-d/A) & 0.766 & 0.797 & \\
$1-\exp (-d / \Lambda)$ & 0.234 & 0.203 &
\end{tabular}

of previous considerations, the changes reflect the surface concentration variations of the sample. At the end of the experiment, the surface showed a good quality $(1 \times 1)$ LEED pattern as at the beginning. The $b / p$ depths ratios of $\mathrm{Ni} L V V$ at $718 \mathrm{eV}$ to $\mathrm{Cu} L V V$ at $920 \mathrm{eV}$, obtained at the end of each heating stage, for the investigated temperatures are collected in Table II. The Auger data are averaged over several separate and independent sets of measurements. The value of $b / p$ ratio slightly increases at $1073 \mathrm{~K}$ indicating that the concentration of copper decreases with temperature. The surface-bulk thermodynamic equilibrium was likely achieved at high temperatures, i.e. with the range of $1006 \mathrm{~K}\left(733^{\circ} \mathrm{C}\right)$ to $1073 \mathrm{~K}$ $\left(800^{\circ} \mathrm{C}\right)$. The composition of the sample surface was determined using two simple models. A rough model assumes homogeneous distribution of components in the probed region, i.e. approximately $0.85 \div 1.00 \mathrm{~nm}$ in depth (Table III). The average (or apparent) composition of the surface layer was determined using Eq. (3). The obtained values indicate small enrichment of copper in the surface zone and 
a bulk concentration of copper equal to 0.87 at.\% The second model assumes that segregant enrichment exists only in the outermost atomic layer and that the composition of subsequent layers corresponds to the bulk. Introducing values from Table III, we have

$$
C_{\mathrm{Cu}}^{\mathrm{s}}=\frac{1-C_{\mathrm{Cu}}^{\mathrm{b}}\left(0.766+\frac{i}{i_{0}} 0.797\right)}{0.234+\frac{i}{i_{0}} 0.203} .
$$

Taking for the $\mathrm{b} / \mathrm{p}$ depths ratio of $i_{0}=0.52$ from the reference spectra, Eq. (8) can be used with one adjustable parameter, $C_{\mathrm{Cu}}^{\mathrm{b}}$. To determine the surface coverage, the value of $C_{\mathrm{Cu}}^{\mathrm{av}}$ at $1073 \mathrm{~K}\left(800^{\circ} \mathrm{C}\right)$, i.e. 0.87 at.\%, was used as $C_{\mathrm{Cu}}^{\mathrm{b}}$.

\subsection{Surface segregation of sulphur}

Segregation of sulphur to the $\mathrm{Cu}_{x} \mathrm{Ni}_{1-x}(100)$ surface could be observed in the sample for which a reduced exposure to oxygen was performed during the cleaning process. Appearance of sulphur on the sample surface was observed during heating at higher temperatures. The evolution of LEED patterns was found as originating from the $(1 \times 1)$ clean surface structure through $p(2 \times 2)$ to $c(2 \times 2)$. The last structure corresponds to the saturated surface layer in this system. The presence of the patterns is not surprising [26] and in analogy with $c(2 \times 2) \mathrm{S} / \mathrm{Ni}(100)$ or $c(2 \times 2) \mathrm{S} / \mathrm{Cu}(100)$ the atoms of sulphur occupy fourfold hollow sites. The "Cu+Ni" mixed site would involve three $\mathrm{Cu}$ atoms and one $\mathrm{Ni}$ atom or four $\mathrm{Cu}$ atoms in the case of uniformly distributed $\mathrm{Ni}$ atoms in the first layer. However, the results of Auger measurements (described later in this section) indicate that the competition between sulphur and copper atoms occurs and that configurations with more than one $\mathrm{Ni}$ atom cannot be excluded.

For the sample with sulphur in the subsurface region, the Auger transition of $\mathrm{S} \mathrm{L}_{3} \mathrm{M}_{23} \mathrm{M}_{23}$ at $154 \mathrm{eV}$ appeared in the spectrum during heating. The sulphur content in the $\mathrm{Cu}_{x} \mathrm{Ni}_{1-x}(100)$ alloy as bulk impurity was evaluated as to be smaller than $20 \mathrm{ppm}$. The appearance of sulphur on the surface was investigated in measuring the sulphur Auger signal as a function of time at a given temperature. The investigated temperatures were in the indicated order: $960 \mathrm{~K}$ $\left(687^{\circ} \mathrm{C}\right), 987 \mathrm{~K}\left(714^{\circ} \mathrm{C}\right), 1056 \mathrm{~K}\left(783^{\circ} \mathrm{C}\right), 1100 \mathrm{~K}\left(827^{\circ} \mathrm{C}\right), 983 \mathrm{~K}\left(710^{\circ} \mathrm{C}\right), 1002 \mathrm{~K}$ $\left(729^{\circ} \mathrm{C}\right)$ and $1063 \mathrm{~K}\left(790^{\circ} \mathrm{C}\right)$. After each segregation run, the sulphur surface layer was removed by argon ion bombardment. Prior to the last experiment performed at $1063 \mathrm{~K}\left(790^{\circ} \mathrm{C}\right)$, the CuNi sample was taken out of the UHV chamber and mechanically polished to eliminate the sulphur-depleted zone. The sulphur signal $I_{\text {S154 }}$ was measured using the $\mathrm{p} / \mathrm{p}$ height. The normalized sulphur Auger intensities, defined as $H=I_{\mathrm{S} 154} /\left(I_{\mathrm{Ni718}}+i_{0} I_{\mathrm{Cu} 920}\right)$, where $i_{0}$ is the pure elemental ratio, $I_{\mathrm{Ni718}}^{0} / I_{\mathrm{Cu} 920}^{0}$, here equal to 0.52 , are shown in Fig. 3 . The H's exhibit a monotonic increase with time without any plateau. Longer times were required to attain saturation. The data in Fig. 3 show that after the third segregation experiment on the same sample, the segregation kinetics become slower. This results from the progressive depletion of sulphur from the near surface region [27]. This is confirmed by the result of the last experiment at $1063 \mathrm{~K}$, which was done after mechanical elimination of the sulphur-depleted zone. At the end of the presented runs, the ratio of nickel to copper Auger signals, $I_{\mathrm{Ni718}} / I_{\mathrm{Cu} 920}$, depending on temperature, 

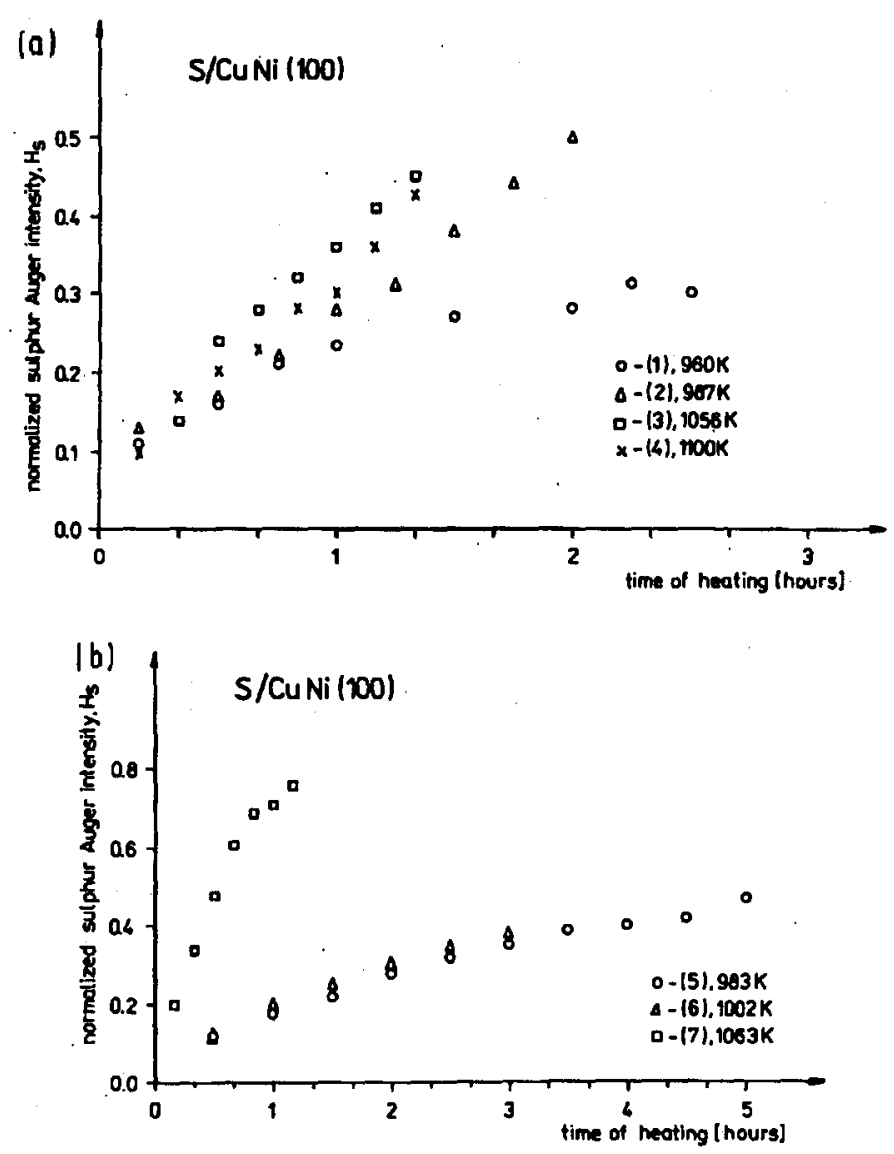

Fig. 3. Sulphur segregation runs for the $\mathrm{Cu}_{x} \mathrm{Ni}_{1-x}(100)$ alloy. The ordinate is the normalized sulphur Auger intensity, $H_{\mathrm{S}}$, i.e. $I_{\mathrm{S} 154} /\left(I_{\mathrm{Ni718}}+0.52 I_{\mathrm{Cu} 920}\right)$. The numbers in parentheses in the figure indicate the order in which the experiments were performed. Note that the time scale in (b) is larger than in (a) by a factor of two.

was in the range of $0.078 \div 0.083$. These values are larger than that obtained for the clean surface (Table II). Although an exact quantitative analysis is impossible without calibration of attenuation of the signals by sulphur, it is clearly deduced from the ratio that the concentration of nickel is larger on the sulphur-containing surface than on the sulphur-free surface. This suggests that $\mathrm{Cu}$ atoms were moved away from the topmost surface layer in the competition with sulphur atoms.

\subsection{Discussion}

In the case of the small segregating effect, as the one observed here for $\mathrm{Cu}$, the quantification of the AES measurements become critical and the question of accuracy of quantification appears. In carefully controlled experiments, relative changes of surface concentration can be determined with reproducibility better than $1 \%$ (e.g. [28]). The recorded changes in the $\mathrm{p} / \mathrm{p}$ height (or $\mathrm{b} / \mathrm{p}$ depth) of 
copper (and nickel) Auger signals correspond to changes in the surface concentration of the element, indicating that the surface concentration of $\mathrm{Cu}$ is larger at $1006 \mathrm{~K}\left(733^{\circ} \mathrm{C}\right)$ than at $1073 \mathrm{~K}\left(800^{\circ} \mathrm{C}\right)$. Such behavior rules out the existence of the crossover phenomenon for our $\mathrm{Cu}_{x} \mathrm{Ni}_{1-x}(100)$ alloy. From our study, the systematic error in the Auger analysis could not be determined with an appropriate accuracy. Under the assumption of ideal preparation of the sample, i.e. with the exact value of $x=0.90$, the systematic error could be evaluated as equal to $3 \%$.

\section{Conclusions}

This study showed: (i) a small segregation of $\mathrm{Cu}$ to the (100) surface of the $\mathrm{Cu}_{x} \mathrm{Ni}_{1-x}$ alloys, ruling out a crossover phenomenon in surface segregation on $\mathrm{Cu}-\mathrm{Ni}$ alloy and (ii) a strong segregation of sulphur, with the formation of ordered overlayer structures, and enrichment of $\mathrm{Ni}$ on the sulphur-covered surface.

\section{References}

[1] B. Hofmann, D. Borgmann, G. Wedler, in: Diffusion at Interfaces: Microscopic Concepts, Eds. M. Grunze, H.J. Kreuzer, J.J. Weiner, Springer series in Surface Sciences, Vol. 12, Springer Verlag, Berlin 1988, p. 21.

[2] G. Treglia, B. Legrand, P. Maugain, Surf. Sci. 225, 319 (1990).

[3] P.R. Webber, M.A. Morris, Z.G. Zhang, J. Phys. F, Metal. Phys. 16, 413 (1986).

[4] W.D. Roos, G.N. van Wyk, J. du Plessis, Surf. Interface Anal. 20, 95 (1993).

[5] Yi-Chen Cheng, Phys. Rev. B 34, 7400 (1986).

[6] T. Sakurai, T. Hashizume, A. Jimbo, A. Sakai, S. Hyado, Phys. Rev. Lett. 55, 514 (1985).

[7] K. Watanabe, M. Hashiba, T. Yamashino, Surf. Sci. 69, 721 (1971).

[8] J.J. Burton, C.R. Helms, R.S. Polizzotti, J. Vac. Sci. Technol. 13, 204 (1976).

[9] R.P. Frankenthal, D.J. Siconolf, Sürf. Sci. 119, 331 (1982).

[10] M.P. Seah, W.A. Dench, Surf. Interface Anal. 1, 2 (1979).

[11] S. Tanuma, C.J. Powell, D.R. Penn, Surf. Interface Anal. 20, 77 (1993).

[12] II. Hilferink, E. Lang, K. Heinz, Surf. Sci. 93, 398 (1980).

[13] H.E. Bishop, Surf. Interface Anal. 15, 27 (1990).

[14] R.G. Musket, W. McLean, C.A. Colmenares, D.M. Makowiecki, W.J. Siekhaus, Appl. Surf. Sci. 10, 143 (1982).

[15] M. Grunze, H. Ruppender, O. Elshazly, J. Vac. Sci. Technol. A 6, 1266 (1988).

[16] G.C. Allen, P.M. Tucker, R.K. Wild, Surf. Sci. 68, 469 (1977).

[17] L.E. Davis, N.C. MacDonald, P.W. Palmberg, G.E. Riach, R.E. Weber, Handbook of Auger Electron Spectroscopy, 2nd ed., Physical Electronics Industries, Edina 1976.

[18] H. Shimizu, M. Ono, K. Nakayama, Surf. Sci. 36, 817 (1973).

[19] P.S. Ho, J.E. Lewis, H.S. Wildman, J.K. Howard, Surf. Sci. 57, 393 (1976).

[20] G.K. Wehner, in: Methods of Surface Analysis, Ed. A.W. Czanderna, Elsevier, New York 1975, p. 5.

[21] R. Shimizu, N. Saeki, Surf. Sci. 62, 751 (1977).

[22] G. Betz, Surf. Sci. 92, 283 (1980). 
[23] G.K. Wehner, G.S. Anderson in: Handbook of Thin Film Technology, Eds. L.I. Maissel, R. Glang, McGraw Hill Hook Company, New York 1970.

[24] P.R. Webber, D. Chadwick, Surf. Sci. 94, L151 (1980).

[25] P. Godowski, L. Kepinski, J. Rudny, J. Mat. Sci. Lett. 7, 515 (1988).

[26] M.L. Shek, Surf. Sci. 149, L39 (1985).

[27] G. Luckman, L.R. Adler, W.R. Graham, Surf. Sci. 121, 61 (1982).

[28] C.J. Powell, M.P. Seah, J. Vac. Sci. Technol. A 8, 735 (1990). 